\title{
The Effect of Zero Copayments on Medication Adherence in a Community Pharmacy Setting
}

Melissa Jimenez, PharmD ${ }^{1}$; Goar Alvarez, PharmD, CPh, FASCP1; Albert Wertheimer, PhD, MBA'; Leanne Lai, PhD'; Leroy Koh, PharmD, MPH'; Dainelys Martinez, PharmD, MPH'; Bushra Hijazi, PhD, MClinPharm ${ }^{3}$; Mark Weinstein, JD, CPA, CEBS, LLM, MPH

${ }^{1}$ Nova Southeastern University College of Pharmacy, Ft. Lauderdale, FL; ${ }^{2}$ Houston Methodist Hospital, Houston, TX; ${ }^{3} J o r d a n$ University of Science and Technology College of Clinical Pharmacy, Irbid, Jordan; ${ }^{4}$ Independent Colleges and Universities Benefits Association, Orlando, FL

When the study was conducted, Dr. Leroy Koh and Dr. Bushra Hijazi were affiliated with Nova Southeastern University College of Pharmacy. They have since relocated to their respective organizations.

\section{ABSTRACT}

Background: Prescription medication copayments can be a financial burden to many patients. When patients cannot afford their medications, they may become nonadherent, and as a result, this can lead to an increase in chronic disease complications and healthcare costs. Objective: The objective of this study was to determine if zero copayments have an effect on medication adherence in a community pharmacy. Methods: This retrospective cohort study examined the prescription refill records of patients who filled specific generic medications for hypertension, hyperlipidemia, and gastroesophageal reflux disease (GERD) in 2016 at the NSU Clinic Pharmacy. The adherence rates of patients with zero copayments were compared to the adherence rates of patients with copayments greater than $\$ 0$. Adherence was determined by calculating the proportion of days covered (PDC). Patients were considered adherent if their PDC was greater than or equal to $80 \%$. Results: GERD patients with no copayments had average PDC ratios of $87.4 \%$ and were statistically significantly more adherent than GERD patients with copayments, who had average PDC ratios of $76.7 \%(P=0.042)$. Hyperlipidemia and hypertension patients with no copayments had average PDC ratios of $89.3 \%$ and $90.3 \%$, respectively, and those with copayments had PDC ratios of 85.3\% ( $P=0.314)$ and $87.9 \%(P=0.534)$. Conclusion: Overall, patients with $\$ 0$ copayments had higher adherence rates than patients with copayments greater than \$O. GERD patients with no copayments were significantly more adherent than GERD patients with copayments. However, no statistically significant difference was found between patients with or without copayments in the hyperlipidemia and hypertension cohorts. Further studies are recommended to analyze additional factors that may influence medication adherence.

\section{INTRODUCTION}

Prescription medication nonadherence is a major health problem in the United States. Previous research studies have shown that medication nonadherence leads to poor health outcomes and chronic disease state complications, resulting in increased utilization of physician office visits, urgent care and emergency room services, and hospitalizations, as well as increased morbidity and mortality. ${ }^{1-5}$ It is estimated that medication nonadherence in the United States is responsible for about $10 \%$ of hospitalizations and at least 125,000 deaths annually. ${ }^{5}$ As a result, medication nonadherence leads to an overall increase in healthcare expenditures, costing the healthcare system between $\$ 100$ billion to $\$ 289$ billion per year..$^{2-3,5}$

Medication nonadherence can be attributed to multiple causes, such as patient sociodemographic characteristics, economic factors, patient beliefs and perceptions, cognitive function, medication adverse effects, disease severity, medication regimen complexity, treatment duration, access to care,

Corresponding author: Melissa Jimenez, PharmD Nova Southeastern University, NSU Clinic Pharmacy 3200 S. University Dr., Ft. Lauderdale, FL 33328

Email: meliijime@nova.edu prescription drug coverage, etc. ${ }^{3,5-6}$ Medication cost is considered one of the most significant barriers to adherence for many patients. Several studies suggest that an inverse relationship exists between prescription drug copayments and medication adherence. ${ }^{1-3,7-10}$ When patients cannot afford to purchase their medications, they may become nonadherent to their medication regimens by skipping doses, splitting tablets, or stopping their medications altogether. This can lead to poor health outcomes and increased healthcare costs. ${ }^{1-2,7,8,10}$

Hypertension and hyperlipidemia are among two of the most common chronic medical conditions for which prescriptions are filled in community pharmacies in the United States. Adherence to antihypertensive and antihyperlipidemic medications is critical to the management of these mostly asymptomatic conditions in order to prevent and reduce the risk of future cardiovascular events. ${ }^{11-14}$ Uncontrolled hypertension can lead to serious cardiovascular complications, such as stroke, heart failure, atrial fibrillation, coronary artery disease, and peripheral vascular disease. ${ }^{11}$ Likewise, uncontrolled hypercholesterolemia can increase the risk of coronary and cerebrovascular events. Complications from uncontrolled hypertension and hyperlipidemia can ultimately increase the risk of cardiovascularrelated morbidity and mortality. ${ }^{13,15}$ For example, poor statin use and uncontrolled hypercholesterolemia alone is responsible for 
nearly 635,000 new coronary events, almost 800,000 strokes, and about one in six deaths annually. ${ }^{15}$

Gastroesophageal reflux disease (GERD) is another health condition frequently seen in community pharmacies. GERD is mostly a symptomatic condition in which patients usually experience heartburn and acid reflux. Adherence to acidreducing medications is important in the treatment of GERD. However, studies show that treatment failure is high among GERD patients due to medication nonadherence. ${ }^{6,16}$ Uncontrolled GERD can lead to complications such as esophagitis, esophageal erosions, Barrett's esophagus, and esophageal adenocarcinoma.,16-17 GERD is the most expensive gastrointestinal disease in the U.S. and is associated with over $\$ 10$ billion in direct medical and drug costs. ${ }^{17}$

Prior research studies suggest that medication adherence can be improved by reducing patient copayments and out-of-pocket costs. ${ }^{1,3,5,18-19}$ However, there is a limited amount of published research available regarding whether $\$ 0$ copayments have an impact on medication adherence, particularly in patients with commercial insurance. The objective of this study was to determine if zero copayments had an effect on medication adherence on prescriptions filled in a community pharmacy setting.

\section{METHODS}

\section{Data Source and Study Design}

This retrospective cohort study was approved by the Institutional Review Board at Nova Southeastern University. The study was conducted at the university's full-service community pharmacy on campus in Fort Lauderdale, Florida. The pharmacy's prescription refill records were used to determine the medication adherence rates of patients who filled specific generic medications for hypertension, hyperlipidemia, and GERD.

\section{Subjects}

Adult patients aged $\geq 18$ years who filled at least two prescriptions between January $1^{\text {st }}, 2016$ through December $31^{\text {st }}$, 2016 for any of the following disease states and medications were included in the study: hypertension (lisinopril, losartan), hyperlipidemia (atorvastatin, simvastatin), and GERD (omeprazole, pantoprazole). Patients less than 18 years of age and patients who became deceased in 2016 during the study period were excluded from the study. For each disease state, patients were categorized into either the treatment group or the control group based on their copayments. The treatment group consisted of patients with zero copayments for their medications, and the control group included patients with copayments greater than $\$ 0$ for their medications. All patients included in the study had commercial insurance plans.

\section{Patient Demographics and Baseline Characteristics}

Patient demographics and baseline characteristics were compared between zero-copayment and copayment groups for each disease state. The variables analyzed included age, gender, number of concurrent medications, and whether patients were new or continuous patients to therapy. Patients were classified as new patients if they started the study medication during any month in 2016, and patients were considered to be continuous patients if they started the study medication any time before 2016.

\section{Adherence}

For each patient, medication adherence was determined by calculating the Proportion of Days Covered (PDC). PDC is the preferred method of measuring medication adherence for the chronic diseases discussed in this research study and is supported by the Pharmacy Quality Alliance, the Centers of Medicare and Medicaid Services, and the Centers for Disease Control and Prevention. ${ }^{20-21}$ The following formula was used to calculate PDC:

PDC $=($ Number of Days in Period "Covered" / Number of Days in Period) $\times 100 \%$

The numerator refers to the number of days during the study period in which patients had medication based on pharmacy pick up dates and days' supply. Meanwhile, the denominator refers to the number of days of the study period for each patient (i.e. 365 days for continuous patients, and the number of days from the index date in which the patient first picked up the medication in 2016 until the end of the year for new patients). Patients were considered to be adherent if their PDC was greater than or equal to $80 \%$, and patients were classified as nonadherent if their PDC was less than $80 \%$. The PDC threshold of $80 \%$ or greater is considered to be the goal adherence rate for most chronic disease states in which medications are believed to provide the most clinical benefit to patients. ${ }^{20-21}$

\section{Statistical Analyses}

A series of descriptive measures associated with demographic and baseline characteristics were provided as counts, percentage means, and standard deviations. Chi-square tests were used to assess the statistical significance of differences for categorial variables. Differences in medication adherence rates between zero-copayment and copayment populations were compared using t-test. A critical value of 0.05 was set as the threshold for statistical significance.

\section{RESULTS}

There was a total of 320 unique patients that met the inclusion criteria. One patient was excluded from the study due to death during the study period, and one patient was excluded due to having an age less than 18 years of age. It is important to note that about a third of the patients belonged to more than one disease cohort.

As shown on Table 1, the hypertension cohort consisted of 151 patients, of which 134 patients had no copayments (i.e. the treatment group), and 17 patients had copayments greater than $\$ 0$ (i.e. the control group). The mean age for the treatment and control groups were 59.21 years and 54.29 years, respectively. 
The hyperlipidemia cohort consisted of 169 patients, in which 154 patients had \$0 copayments, and 15 patients had copayments greater than $\$ 0$. The mean age for both the treatment and control groups were 60.31 and 60.47 years, respectively. Meanwhile, the GERD cohort consisted of 104 patients, of which 87 had no copayments, and 17 patients had copayments greater than $\$ 0$. The treatment group had a mean age of 56.49 years, while the control group had a mean age of 49.05 years.

Overall, patients with no copayments had higher adherence rates than patients with copayments greater than zero dollars; however, no statistically significant differences were found between patients with and without copayments for the hyperlipidemia and hypertension patients, as illustrated in Table 2. On the other hand, within the GERD cohort, there was a statistically significant difference between the treatment and control groups: patients with zero-dollar copayments had an average PDC of $87.4 \%$, while patients with copayments greater than $\$ 0$ had an average PDC of $76.7 \%(P=0.042)$.

\section{DISCUSSION}

Our study results showed that the zero-dollar copayment design significantly improved the adherence rates of GERD patients. Similar results were found in the study conducted by Cohen et. al., in which dispensing rates increased as copayments were eliminated for some medications, including those for GERD; as zero copayments went into effect, prescription filling rates by patients increased, thus increasing medication adherence. ${ }^{9}$ In addition, in the literature review conducted by Domingues et. al., it was found that patients less than 60 years of age are more likely to be less adherent to medications for symptomatic conditions. ${ }^{6}$ This observation can be seen in our study, in which GERD patients with copayments had an average age less than 60 years and were nonadherent to their GERD medications.

Conversely, our study found that a decrease in copayments was not associated with an increase in adherence rates in hypertension or hyperlipidemia. One of the reasons for the lack of statistically significant differences within the hypertension and hyperlipidemia cohorts might be the fact that most copayment patients had very small copayment amounts, as shown in Table 2 and Figure 1. It was found that $65.6 \%$ of hypertensive and hyperlipidemic patients (i.e. 21 patients) in the treatment groups had copayments of $\$ 5.00$ or less, $21.9 \%$ (i.e. seven patients) had copayments between $\$ 5.01$ and $\$ 10.00$, and only $9.4 \%$ (i.e. four patients) had copayments between $\$ 10.01$ and $\$ 20.00$. None of the patients had copayments $\geq \$ 20$. Because most copayments were minimal, prescription costs may not have been a barrier to medication adherence for patients in the hypertension and hyperlipidemia cohorts.

Another possible explanation why copayments may not have significantly impacted the adherence rates of hypertension and hyperlipidemia patients might be due to disease severity, comorbidities, and patient knowledge and awareness of the consequences of nonadherence to cardiovascular medications.
The studies conducted by Schneeweiss et. al. and Wang et. al. found that increased copayments, coinsurance, and patient outof-pocket costs decreased adherence; however, the adherence rates of post-myocardial infarction patients and patients with higher cardiovascular comorbidities were not affected by increased medication costs. The authors of both studies mention that the patients may have been more aware of the importance of medication adherence to prevent future adverse cardiovascular events such as myocardial infarction, stroke, and death. ${ }^{10,14}$ It is unknown whether the patients in our study experienced high cardiovascular disease severity and comorbidities; however, since the pharmacy is located within an academic institution of higher learning, many of the patients included in our study might have a better understanding of the importance of taking their medications as prescribed to prevent serious cardiovascular events in the future.

Wang et. al. suggested that the lack of over-the-counter (OTC) alternatives for hypertension and hyperlipidemia could play a role in influencing medication adherence rates for cardiovascular patients. ${ }^{10}$ The medications typically prescribed for hypertension and hyperlipidemia, including the ones analyzed in this study, are available only by prescription in the United States, and patients have no OTC alternatives to treat their condition; therefore, patients with hypertension and hyperlipidemia are more likely to fill their prescription medications. ${ }^{10}$ In contrast, a number of proton pump inhibitors, including omeprazole, are available over-the-counter for GERD. It is possible that some of the patients in our study could have been taking OTC proton pump inhibitors or other OTC GERD medications such as histamine H2receptor antagonists (ex. ranitidine); as a result, they may not have refilled their prescription GERD medications, thus affecting our study's adherence results for the GERD patients.

\section{Limitations}

Since our study utilized prescription refill records at a single pharmacy, it is not known whether patients utilized another pharmacy for any of their refills for their medications. Also, as mentioned above, it is possible that some GERD patients may have used OTC proton pump inhibitors or other GERD medication alternatives, which is information that is unobtainable from pharmacy refill records. In addition, per the literature, prescription refill records may not be an accurate measure to assess true medication adherence because refill and pick up records assume that patients are taking their medications. However, it is impossible to know whether patients are truly taking their medications as prescribed without direct observation.

\section{CONCLUSION AND FUTURE IMPLEMENTATIONS}

Although the sample sizes of our study population were rather small, we can nevertheless conclude that the presence of a zerodollar copayment structure increased adherence rates for patients with the symptomatic condition of GERD, as there was a statistically significant difference in the PDC rates between the treatment group and the control group. Based on our results, we 
can recommend that prescription benefit plans and health insurers consider removing copayments for symptomatic conditions such as GERD. Albeit it may cost insurance payers more money upfront, such a policy has the potential to save much more money in the long run because it can lead to increased medication adherence, which can result in fewer hospitalizations and other costly healthcare interventions.

Additional studies are recommended to analyze other contributing factors that might affect adherence, such as geographic location, socioeconomic status, education, health literacy, race, ethnicity, language, etc. Also, it would be reasonable to evaluate the impact that pharmacists can have in affecting medication adherence rates. Previous studies have shown that pharmacists play an important role in increasing adherence rates through medication therapy management, patient counseling, and education. . $^{3-5,22-23}$

When it comes to prescription medication costs, third-party insurance payers can influence medication adherence when these entities establish their drug formularies and copayment tier structures. Previous studies have shown that medication costs affect adherence rates. By decreasing patient prescription copayments and medication out-of-pocket costs, third-party insurance payers can help increase medication adherence and improve health outcomes, which may result in decreased health complications, hospitalizations, morbidity, and mortality, and lead to an overall decrease in healthcare costs and an increase in savings in the long run. ${ }^{1-2,5,7-8,10,14,17-19}$

Disclaimers: The views expressed in this manuscript are solely our own and are not official positions of the authors' corresponding institutions.

Disclosures: The authors of this manuscript have nothing to disclose concerning possible financial or personal relationships with commercial entities that may have a direct or indirect interest in the subject matter of this research study. 


\section{REFERENCES}

1. Clark B, DuChane J, Hou J, et. al. Evaluation of increased adherence and cost savings of an employer value-based benefits program targeting generic antihyperlipidemic and antidiabetic medications. J Manag Care Pharm. 2014; 20(2):141-150.

2. Gourzoulidis G, Kourlaba G, Stafylas P, et. al. Association between copayment, medication adherence and outcomes in the management of patients with diabetes and heart failure. Health Policy. 2017; 121(4):363-377.

3. luga AO, McGuire MJ. Adherence and health care costs. Risk Manag and Healthc Policy. 2014; 7:35-44.

4. Davis EM, Packard KA, Jackevicius CA. The pharmacist role in predicting and improving medication adherence in heart failure patients. J Manag Care Pharm. 2014; 20(7):741-755.

5. Viswanathan M, Golin C, Jones C. et. al. Interventions to improve adherence to self-administered medications for chronic diseases in the United States: a systematic review. Ann Intern Med. 2012; 157:785-795.

6. Domingues G, Moraes-Filho JPP, Noncompliance is an impact factor in the treatment of gastroesophageal reflux disease. Expert Rev Gastroenterol Hepatol. 2014; 8(7):761-765. 7. Gibson TB, Mark TL, McGuigan KA, et. al. The effects of prescription drug copayments on statin adherence. Am J Manag Care. 2006;12:509-517.

8. Eaddy MT, Cook CL, O’Day K, et. al. How patient costsharing trends affect adherence and outcomes: a literature review. $P$ T. 2012; 37(1):45-55.

9. Cohen D, Alam MF, Dunstan FD et. al. Abolition of prescription copayments in Wales: an observational study on dispensing rates. Value Health. 2010; 13(5):675-680.

10. Wang V, Liu CF, Bryson CL, et. al. Does medication adherence following a copayment increase differ by disease burden? Health Serv Res. 2011; 46(6 Pt 1):1963-1985.

11. Bloch MJ, Basile J. Cardiovascular risks of hypertension. UpToDate. Jan 2018. Accessed August 21, 2018.

12. Maciejewski ML, Bryson $\mathrm{CL}$, Perkins $\mathrm{M}$, et. al. Increasing copayments and adherence to diabetes, hypertension, and hyperlipidemic medications. Am J Manag Care. 2010; 16(1):e20-34.
13. Doshi JA, Zhu Jingsan, Lee B, et. al. Impact of a prescription copayment increase on lipid lowering medication adherence in veterans. Circulation. 2009: 119(3):390-397.

14. Schneeweiss S, Patrick AR, Maclure M, et. al. Adherence to statin therapy under drug cost sharing in patients with and without acute myocardial infarction: a population-based natural experiment. Circulation. 2007; 115(16):2128-2135. 15. Gatwood J, Bailey JE. Improving medication adherence in hypercholesterolemia: challenges and solutions. Vasc Health Risk Manag. 2014; 10:615-625.

16. Subramanian CR, Triadafilopoulos G. Refractory gastroesophageal reflux disease. Gastroenterol Rep. 2015; 3(1):41-53.

17. Gosselin A, Luo R, Lohoues $H$, et. al. The impact of proton pump inhibitor compliance on health-care resource utilization and costs in patients with gastroesophageal reflux disease. Value Health. 2009; 12(1):34-39.

18. Pittman DG, Chen W, Bowlin SJ, et. al. Adherence to statins, subsequent healthcare costs, and cardiovascular hospitalizations. Am J Cariol. 2011; 107:1662-1666.

19. Chen SY, Shah SN, Lee YC, et. al. Moving branded statins to lowest copay tier improves patient adherence. J Manag Care Pharm. 2014; 20(1):34-42.

20. Centers for Disease Control and Prevention (CDC).

Calculating proportion of days covered (PDC) for

antihypertensive and antidiabetic medications: an evaluation guide for grantees. https://www.cdc.gov/dhdsp/docs/medadherence-evaluation-tool.pdf. Published August 31, 2015. Accessed April 5, 2017.

21. Crowe, M. Do you know the difference between these adherence measures?. Pharmacy Times.

http://www.pharmacytimes.com/contributor/michael-crowepharmd-mba-csp-fmpa/2015/07/do-you-know-the-differencebetween-these-adherence-measures. Published July 5, 2015.

Accessed February 25, 2017.

22. Watanabe JH, Mclnnis T, Hirsch JD. Cost of prescription drug-related morbidity and mortality. Ann Pharmacother. 2018;1-9. doi:10.1177/1060028018765159

23. Pringle JL, Boyer A, Conklin $\mathrm{MH}$, et. al. The Pennsylvania project: pharmacist intervention improved medication adherence and reduced health care costs. Health Aff. 2014;33(8):1444-1452. 
Table 1. Patient Demographics

\begin{tabular}{|c|c|c|c|c|c|c|}
\hline \multirow[b]{2}{*}{$\begin{array}{c}\text { Baseline } \\
\text { Characteristic }\end{array}$} & \multicolumn{2}{|c|}{$\begin{array}{l}\text { Hypertension } \\
\qquad=151\end{array}$} & \multicolumn{2}{|c|}{$\begin{array}{l}\text { Hyperlipidemia } \\
\qquad N=169\end{array}$} & \multicolumn{2}{|c|}{$\begin{array}{c}\text { GERD } \\
N=104\end{array}$} \\
\hline & $\begin{array}{c}\text { Treatment } \\
\text { Group } \\
\text { n = } 134\end{array}$ & $\begin{array}{l}\text { Control } \\
\text { Group } \\
n=17\end{array}$ & $\begin{array}{c}\text { Treatment } \\
\text { Group } \\
\text { n = } 154\end{array}$ & $\begin{array}{l}\text { Control } \\
\text { Group } \\
n=15\end{array}$ & $\begin{array}{c}\text { Treatment } \\
\text { Group } \\
n=87\end{array}$ & $\begin{array}{l}\text { Control } \\
\text { Group } \\
n=17\end{array}$ \\
\hline $\begin{array}{l}\text { Mean Age, } \\
\text { n (Range) }\end{array}$ & $59.21(26-91)$ & $54.29(26-94)$ & $60.31(25-88)$ & $60.47(24-85)$ & $56.49(18-84)$ & $49.06(18-79)$ \\
\hline $\begin{array}{l}\text { Gender } \\
\text { Female, n (\%) }\end{array}$ & $60(44.78)$ & $10(58.82)$ & $70(45.45)$ & $8(53.33)$ & $50(57.47)$ & $10(58.82)$ \\
\hline Male, n (\%) & $74(55.22)$ & $7(41.18)$ & $84(54.54)$ & $7(46.67)$ & 37 (42.53) & $7(41.18)$ \\
\hline $\begin{array}{l}\text { Concurrent } \\
\text { Medications } \\
<5 \text {, n (\%) }\end{array}$ & $89(66.42)$ & $10(58.82)$ & $103(66.88)$ & $9(60)$ & $53(60.92)$ & $11(64.71)$ \\
\hline$\geq 5, \mathrm{n}(\%)$ & $45(33.58)$ & $7(41.18)$ & $51(33.12)$ & $6(40)$ & 34 (39.08) & $6(35.29)$ \\
\hline $\begin{array}{l}\text { New Patients, } \\
\mathrm{n}(\%)\end{array}$ & $29(21.64)$ & $8(47.06)$ & 23 (14.94) & $5(33.33)$ & 27 (31.03) & $8(47.06)$ \\
\hline $\begin{array}{l}\text { Continuous } \\
\text { Patients, n (\%) }\end{array}$ & $105(78.36)$ & $9(52.94)$ & $131(85.06)$ & $10(66.67)$ & 60 (68.97) & $9(52.94)$ \\
\hline
\end{tabular}

GERD = Gastroesophageal Reflux Disease 
Table 2. Adherence Rates by Proportion of Days Covered (PDC)

\begin{tabular}{|c|c|c|c|c|c|c|}
\hline Disease & Group & $\begin{array}{l}\text { Average } \\
\text { Copayment }\end{array}$ & $\mathbf{N}$ & Average PDC & $\begin{array}{l}\text { Standard } \\
\text { Deviation }\end{array}$ & $P$ Value \\
\hline \multirow{2}{*}{ Hypertension } & Treatment & $\$ 0.00$ & 134 & $90.34 \%$ & 14.81 & \multirow{2}{*}{0.534} \\
\hline & Control & $\$ 3.63$ & 17 & $87.90 \%$ & 18.25 & \\
\hline \multirow{2}{*}{ Hyperlipidemia } & Treatment & $\$ 0.00$ & 154 & $89.34 \%$ & 14.39 & \multirow{2}{*}{0.314} \\
\hline & Control & $\$ 6.75$ & 15 & $85.33 \%$ & 17.60 & \\
\hline \multirow{2}{*}{ GERD } & Treatment & $\$ 0.00$ & 87 & $87.37 \%$ & 14.80967 & \multirow{2}{*}{$0.042 *$} \\
\hline & Control & $\$ 5.19$ & 17 & $76.66 \%$ & 18.25181 & \\
\hline
\end{tabular}

GERD = Gastroesophageal Reflux Disease; PDC $=$ Proportion of Days Covered.

* Indicates statistically significant $(P<0.05)$ 
Figure 1. Number of Patients with Copayments

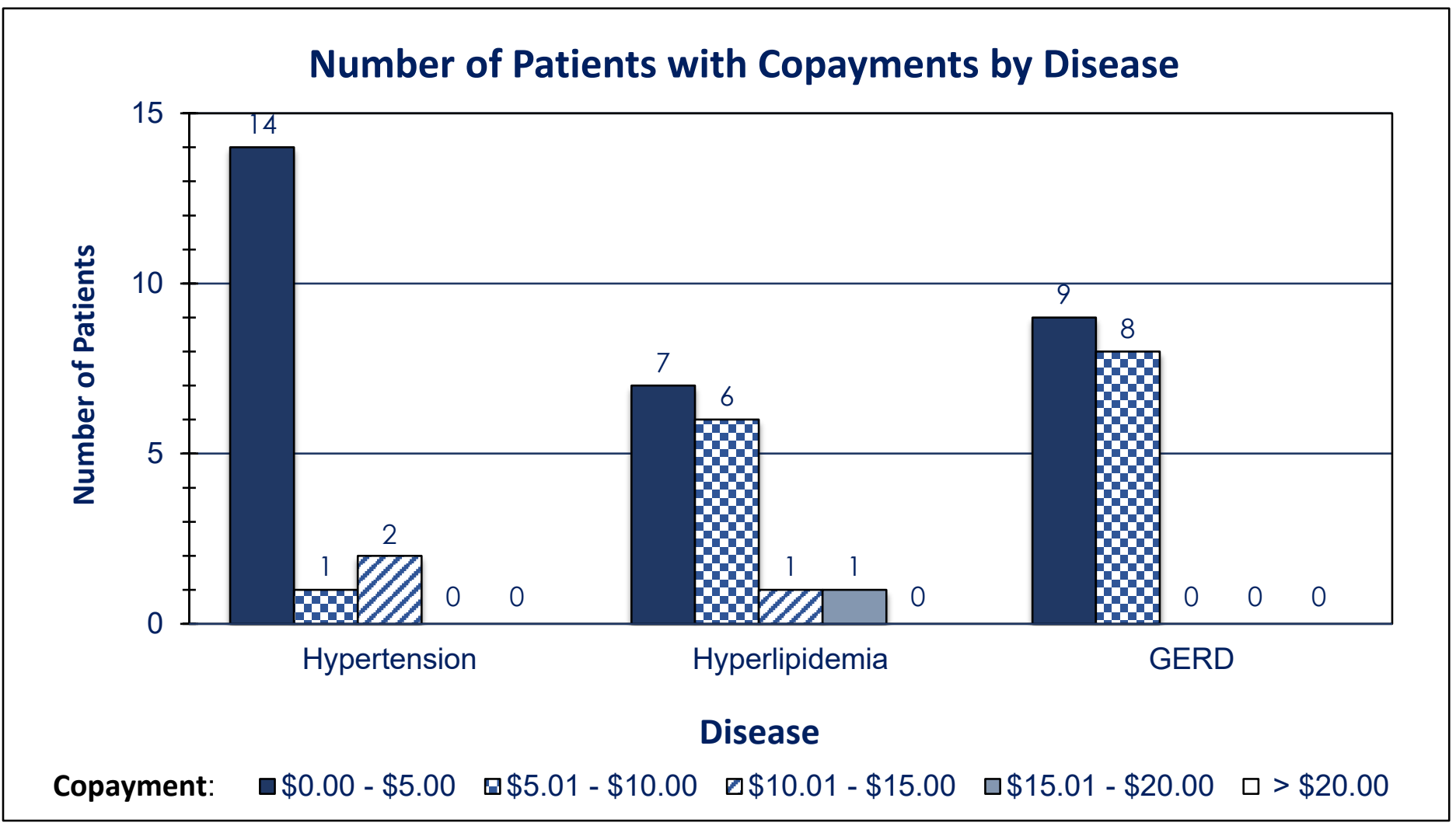

